\title{
MODERNIZATION OF THE METHOD OF LINE-LINE INTERSECTION USING RTN GNSS TECHNOLOGY FOR DETERMINING THE POSITION OF CORNERS OF BUILDINGS
}

\author{
Robert Krzyżek \\ AGH University of Science and Technology, \\ Faculty of Mining Surveying and Environmental Engineering, \\ Department of Geomatics \\ 30 Mickiewicza Al., 30-059 Krakow, Poland \\ e-mail: rkrzyzek@agh.edu.pl
}

\begin{abstract}
Carrying out measurements of buildings with RTN GNSS technology in difficult environmental conditions appears to be a major challenge for many surveyors. Achieving the required accuracy of the position of a building structure is often a difficult, and sometimes even an impossible task to perform. This paper presents an innovative solution to increase the reliability of determining the coordinates of building corners, by modernizing the results obtained from the indirect method of measurement of line-line intersection by the socalled half-angle method. Generally speaking, the half-angle method is to verify the angular values in determined points (corners of buildings) from the method of intersection of the base point lines. Optimization of this method involves reducing deformation of a building, which has been determined in real time, taking into account only the classical method of line-line intersection. In order to obtain optimized measurement results, the conversion of the obtained results to the convergent values relative to the most probable coordinates is performed. Based on a detailed comparative and statistical analyses, it can be concluded that the modernized method of line intersection, employed in the RTN GNSS mode with the half-angle method, greatly improves the reliability of determining corners of buildings ( $\mathrm{X}$ and $\mathrm{Y}$ coordinates), as well as provides an exact reflection of the geometric shape of a structure.
\end{abstract}

Keywords: RTK - RTX - RTN GNSS, half-angle, line-line intersection, measurement control network, measurements of buildings, base points.

\section{INTRODUCTION}

Buildings are one of the most important measurement objects, qualified as field details of the first-order accuracy. The high rank in the hierarchy of topographic structures also imposes high accuracy requirements on buildings. In the surveys of a subject field detail, the wellknown and commonly used measurement techniques are employed, such as e.g. tacheometry. However, other, non-conventional surveying techniques are also accepted, which meet the accuracy criteria laid down for the first-order accuracy. More and more frequently, real-time RTN GNSS measurements are employed with the use of indirect methods of measurement. It should be remembered, though, that a building is a large-size object, which in turn is a counterargument to the use of RTN GNSS technology requiring an open horizon during the 
performance of measurements. For the measurements of buildings in the RTN GNSS mode, difficult measuring conditions, such as urban environment, force to search for better and better technological solutions which would meet the accuracy requirements. Research on the possibility of carrying out measurements of buildings in difficult environmental conditions in real time was conducted by (Ge et al., 2006), who positively assessed the usefulness of modern surveying techniques, but necessarily integrated with classical measurements. A different technological solution was proposed by the author (Krzyżek) in his research. He analyzed the use of indirect method of line-line intersection with an innovative solution - the so-called method of vector addition in RTN GNSS measurements (the results of research experiments on this method have been examined in detail by the author). Such a solution leads to a full geometrical compliance of a building, leaving, however, some doubt as to the reliability of determining the $\mathrm{X}$ and $\mathrm{Y}$ coordinates of building corners. Therefore, the author conducted a further research to increase the reliability of determining these coordinates, presenting the experimental results of the research in this article.

At the beginning, it should be emphasized that the following solutions refer exclusively to one indirect method of measurement employed in the RTN GNSS technology for buildings, i.e. the method of intersection of straight lines. This assumption was proved in Krzyżek (2014).

Each measurement of a building in real time employing an indirect method of measurement of line-line intersection starts from determining a position of the so-called base points. Already at this stage, high accuracy should be taken into account while setting out base points to the appropriate reference line relative to a building corner. One of the most important attributes also influencing the accuracy of determining building corners is the mean base point error. These points are a kind of a foundation of the whole process of determining corners of buildings, which are the bases for more indirect methods and algorithms. Therefore, the base points should be of the measurement control character. Tacheometry, RTN GNSS surveying, or other well-known measurement techniques, are most reasonably used to establish measurement control networks. Recently, however, a new technology has emerged, or in fact a derivative of the RTN GNSS technology, called RTX (Real Time eXtended) using the xFill function. In the case of RTK measurements, when there is a break in the supply of a primary source of adjustments, i.e. of a reference station or VRS, Trimble RTX Technology with the xFill function automatically supports the measurement system, allowing for its continuation over a specified period of time. However, a question remains, whether the accuracy of determining the base points in the RTX mode meets the accuracy requirements imposed on measurement control networks. Upon transfer of the measurements in real time into the RTX mode, an important role in the formation of accuracy of the measurement results is played by the time of their continuation. The problem of verifying the suitability of RTX technology with the xFill function for establishing measurement controls was discussed in detail in Krzyżek (2013 and 2014).

The appropriate use of GNSS systems may also become a development of an aspect associated with the precision of determining base points as a control network. Until recently, the American GPS satellite system was the only one used. Currently, the system of continuously operating reference stations ASG EUPOS, in some regions of the country provides two systems to the users: GPS and GLONASS; there are still works being conducted on expanding the territorial coverage for such a combination of the GNSS systems. It should be noted that some of the commercial networks of reference stations already have the capacity to provide services with the use of GPS and GLONASS together on the whole territory of Poland. Research on the benefits of using two GNSS systems, carried out in various directions, most frequently led to similar conclusions. One of the most important advantages 
of this solution is a significant reduction in the convergence time, even up to $42 \%$ (Zhang et al., 2014). The efficiency of GPS and GLONASS combination is also analyzed by (Cai et al., 2013), who also confirm the aspect of convergence, noting, however, that assuming good satellite geometry in GPS measurements, the combined use of the two satellite systems does not improve significantly the accuracy itself. In contrast, (Pirti et al., 2013) point to the advantages of using two GNSS systems by comparing measurements in a variety of field conditions, i.e. with an open horizon and partially obscured by trees. With reference to these technological solutions, it should be noted that the tests on the functioning of the third European satellite system GALILEO, being built jointly by the European Union and the European Space Agency, are slowly coming to an end. It is scheduled that in 2015 the system will have achieved an operational phase with 18 satellites and, ultimately, 30 satellites should operate by 2020 .

All modern technology and algorithmic solutions, leading to a higher efficiency of measurements in the RTN GNSS mode in difficult environmental conditions, are most needed. This paper presents the author's concept of increasing reliability of determining coordinates of building corners by verifying the angular values obtained at the points determined by intersection of straight lines of the base points. The main objective of the presented research results is to prove that the innovative solution proposed by the author has great significance in minimizing deformation of the studied building, resulting from the use of RTN GNSS technology employing only the classical method of line-line intersection.

\section{ALGORITHM FOR MODERNIZATION OF THE LINE-LINE INTERSECTION METHOD BY THE HALF-ANGLE METHOD}

In order to obtain optimized results of measurements of building corners with RTN GNSS technology employing indirect measurement method of line-line intersection, in the end, the obtained results are converted to a form of a substantial convergence relative to the most probable values. For this purpose, an original solution called the half-angle method was applied. The principle of the half-angle method is based on a theoretical assumption of a mutual relationship of the building walls, and thus a right angle at each corner of the building. Of course, it should be noted at the very beginning, that this solution can be applied only to those buildings which already at the stage of a technical design had an assumption of squareness of the walls. The half-angle method cannot, therefore, be used for buildings or their fragments in which the walls are rounded or have bay windows. If, however, during the execution of the project (for various reasons), deformation of the right angles occurred in the corners of the building, often leading to diversity in the length of the opposite walls, the halfangle method is able to handle these deformations to a large extent, despite its theoretical assumptions, while maintaining the actual geometry of the building.

Explication of the basic assumptions of this novel method has been presented in Figure 1. Below, the most important technical and calculation steps are constituted, generating the algorithm of modernization of the line-line intersection method by the half-angle method:

1. Having performed the measurements of the base points A, B, C, D with RTN GNSS technology and calculations of line-line intersection, we obtain $\mathrm{X}, \mathrm{Y}$ coordinates of the corners of $\mathrm{B}_{\mathrm{i} \text {-ths }}$ buildings.

2. From the obtained coordinates we calculate horizontal angles of the corners of the building $k_{B i}$.

3. We calculate the angular deviation at each corner of the building $f_{k}=100^{g}-k_{B i}$. 
4. We calculate the angular correction for each corner of the building $v_{k}=\frac{f_{k}}{2}$

5. From every corner of the $B_{i-t h}$ building, we calculate the $X$ and $Y$ coordinates of the adjacent points (corners) $\mathrm{B}(\mathrm{i}+1), \mathrm{B}(\mathrm{i}-1)$, using the coordinates of the stand $\left(\mathrm{B}_{\mathrm{i}-\mathrm{th}}\right.$ corner) and reference to the adjacent corner, as well as polar coordinates, or the angle equal to $v_{k}=\frac{f_{k}}{2}$ together with the length equal to the $\mathrm{R}_{\mathrm{i}-\mathrm{th}}$ tie distance to the neighboring point. At this point, attention should be paid to the sign of the angular correction $v_{k z}$ - when laying off the angle from the reference line to a neighboring point (corner) in the clockwise direction - the "+" sign is assumed, and in the opposite direction - the "-". In this way we obtain new coordinates of the neighboring points (corners) of the building, for example B1 (i+1), B2 (i-1).

6. For each corner of the building we perform the activities set out in 5). In this way, we obtain for each additional point (the corner of the building) two positions: B1, B2.

7. In order to obtain a clear position of the point (most likely $\mathrm{X}$ and $\mathrm{Y}$ coordinates), we perform calculations leading to the determination of the weighted average position of the corner of the building

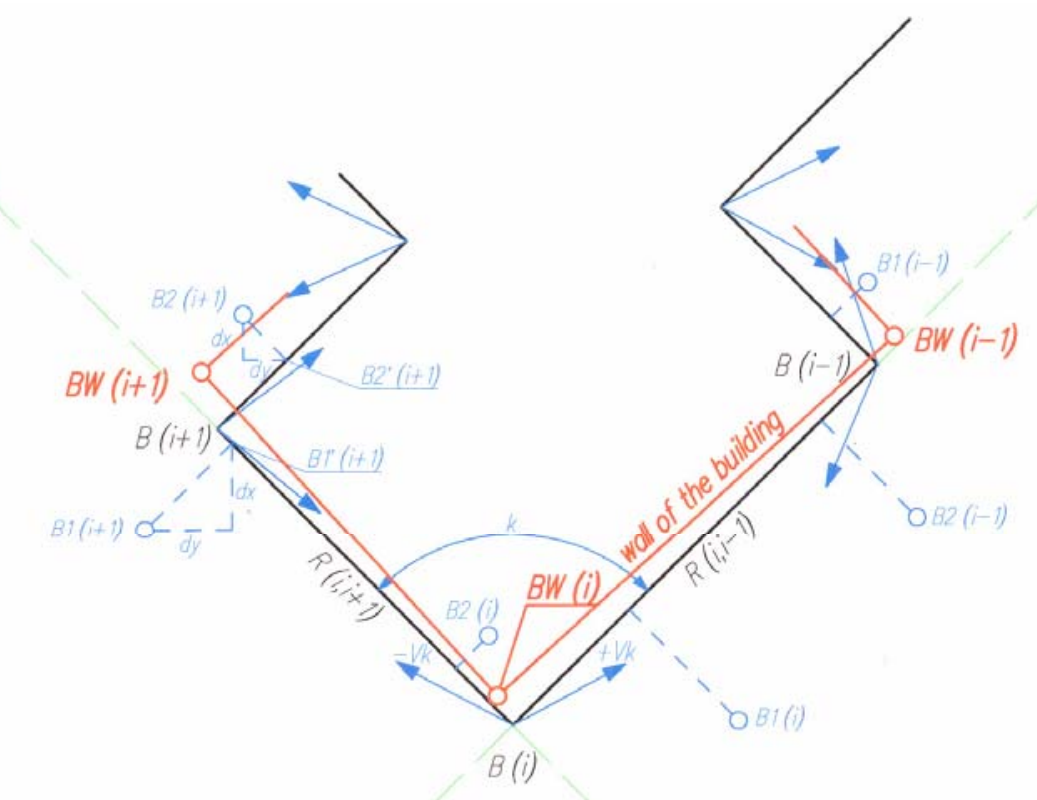

The Legend:

$B(i), B(i+1), B(i-1 \quad$ - corners of the building resulting from the method of intersection of straight lines of the base points A, B, C, D,

$B W(i) B W(i+1), B W(i-1) \quad$ - corners of the building resulting from the modernized method of intersection of straight lines by the half-angle method,

- direction of implementation of the angular correction ("halfangle").

Fig. 1. The modernized method of line-line intersection by the half-angle method. 
8. We calculate the weight for each of the points B1, B2: $p_{x, i_{-} t y}=\frac{1}{d x^{2}}$ and $p_{y, i_{-} t y}=\frac{1}{d y^{2}}$

9. The parameters $d x$ and $d y$ we calculate projecting orthogonally each point $\mathrm{B} 1, \mathrm{~B} 2$ to the reference line, relative to which it was determined, obtaining auxiliary points B1', B2'. The parameters $d x$ and $d y$ are the increments of the coordinates of these sections, e.g. from $\mathrm{B} 1(\mathrm{i}+1)$ to $\mathrm{B} 1$ '(i+1) and from $\mathrm{B} 2(\mathrm{i}+1)$ to $\mathrm{B} 2{ }^{\prime}(\mathrm{i}+1)$.

10. We calculate the $\mathrm{X}$ and $\mathrm{Y}$ coordinates of the corners of the building as weighted average:

$$
\begin{aligned}
X_{B W i_{-} t y} & =\frac{X_{B 1, i_{-} t y} \cdot p_{x 1, i_{-} t y}+X_{B 2, i_{-} t y} \cdot p_{x 2, i_{-} t y}}{p_{x 1, i_{-} t y}+p_{x 2, i_{-} t y}} \\
Y_{B W i_{-} t y} & =\frac{Y_{B 1, i_{-} t y} \cdot p_{y 1, i_{-} t y}+Y_{B 2, i_{-} t y} \cdot p_{y 2, i_{-} t y}}{p_{y 1, i_{-} t y}+p_{y 2, i_{-} t y}}
\end{aligned}
$$

11. We calculate tie distances from the newly determined coordinates of the building corners and compare it with the measurement data (tie distances from the measurement).

Having determined the new coordinates of all the corners of the building, as it appears from the conducted research studies which have been described below, the obtained values are close to the most probable ones. Also, check measurements (tie distances) generally do not exceed the limiting error of the mean error of the linear measurement (open frame tape measure), which is approximately $5-6 \mathrm{~cm}$.

\section{RESEARCH METHODS AND RESEARCH EXPERIMENT}

The test object subject to the experimental surveys was a complex of single-family buildings with associated buildings, e.g. garages, utility buildings. The measurements were carried out for 36 corners in 7 buildings. RTN GNSS technology was employed for the measurements, using the network of reference stations TPI and HiperPro receiver by Topcon. In order to determine the position of the corners of the buildings, an indirect measurement method of line-line intersection was used, as described in detail in Krzyżek (2014). The test object was located in Węgierska Górka in Żywiec County, and the buildings were located on the area of approx. 1.3 hectares (Fig. 2). 

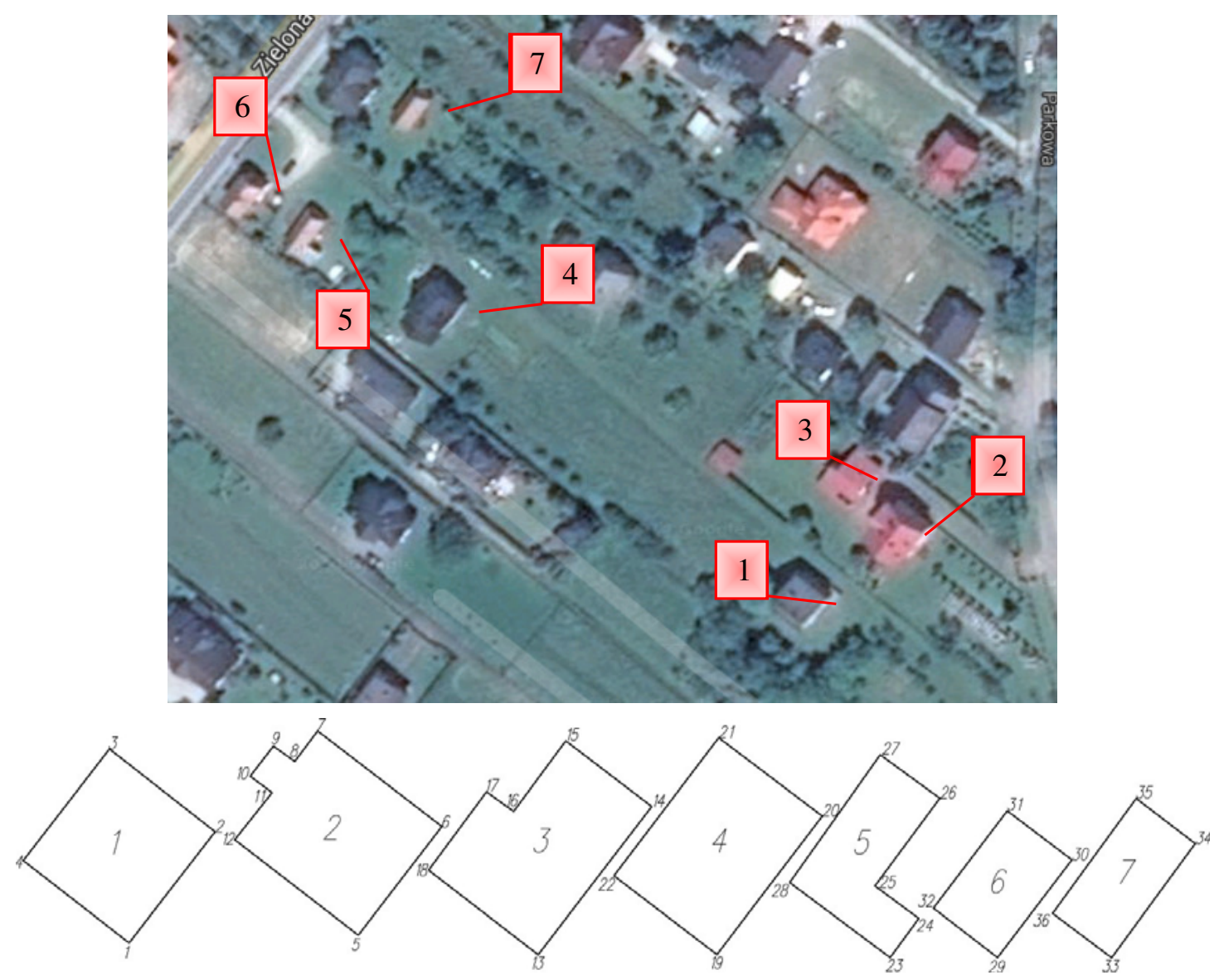

Fig. 2. Location of buildings on the test object in Węgierska Górka

(www.mapy.geoportal.gov.pl/imap, 2014).

Real-time measurement of all the buildings, using the method of line-line intersection, provided a test sample in the form of X, Y coordinates in the PL-2000 system for the analysis. The values of these coordinates for each point were the arithmetic mean of 30 epochs. In order to define the reliability of the determined $\mathrm{X}$ and $\mathrm{Y}$ coordinates, it was necessary to refer them to the values which could be considered as benchmarks. Such parameters were the coordinates of the same corners of the building determined by the tacheometric method tied to the measurement control network. An important factor in this assumption was to retain the uniformity of the coordinates of both the measurement control network and the corners of the building determined in the RTN GNSS mode. Consequently, X, Y coordinates of the measurement control were also determined in the PL-2000 system by a static method, using the same receivers HiperPro tied to the same network of reference stations TPI. As a result of the measurement, and then the adjustment of the coordinates of the measurement control, $\mathrm{X}$ and $\mathrm{Y}$ coordinates were obtained with a mean position error $m_{p}$ at the level of single millimeters, which allowed for the adoption of these points as reference parameters for the results obtained in the RTN GNSS mode.

The last surveying activity in the field was performing check measurements in the form of tie distances. It should be noted that for some of the corners of the buildings there were diversified field conditions. Difficulties occurred both in the RTN GNSS measurements (horizon obscured by buildings, trees - buildings 1,2,3), as well as in the availability of the wall faces of the buildings for tie distance measurements. 
Before proceeding to a detailed analysis of the obtained measurement results, measurement methods were assigned some designations:

- tacheometric method - T,

- line-line intersection method - PP,

- line-line intersection method taking into account the method of vector addition - $P P_{v a}$,

- line-line intersection method modernized by the half-angle method - $P P_{h a}$,

- open frame tape measurement - $R$.

For the obtained measurement results (the coordinates of the building corners) in real time, using the indirect measurement method of the intersection of straight lines, an innovative solution was applied called the half-angle method. As a result of employing this method, each corner of the building received a new position.

As a result, in the first place, the newly obtained $\mathrm{X}, \mathrm{Y}$ coordinates of each corner of the building were evaluated by comparing their values to the reference parameters (the coordinates from the tacheometric measurement). This comparison was mainly intended to present the mutual accuracy relationship of determining sought points between tacheometry and a modernized line-line intersection method with the use of the half-angle method. The obtained coordinate differences $\mathrm{dX}, \mathrm{dY}$ and vector $\mathrm{dL}$ were analyzed in terms of extremes, as well as they were subjected to statistical analysis. The obtained values of coordinate differences and their statistical analysis have been presented in Table 1 .

Another parameter which was subjected both to analysis of obtained extremes as well as statistical analysis was comparison of tie distances as a check measure, with the length of the building wall faces obtained from the coordinates by the $P P_{h a}$ method. These results have been presented in Table 2. This table also summarizes mutual relationships of tie distances in the method of line-line intersection with regard to the method of vector addition (the results of research experiments on this method have been examined in detail by the author). This additional comparison was to demonstrate the scale of the mutual differences between the analyzed methods in the combinations: $T-R, P P_{v a}-R, P P_{h a}-R$.

Statistical analysis, carried out for the coordinate differences $\mathrm{dX}, \mathrm{dY}$ and vector $\mathrm{dL}$ as well as tie distances $\mathrm{dR}$, was begun by defining the null hypothesis $H_{0}$ : the mean value of $\mu$, for the differences in coordinates $d X, d Y$ and vector $d L$ in the combination of the methods - T-PPh, and for the tie distances $d R$ in the combinations of the methods $T-R, P P_{v a}-R, P P_{h a}-R-i$ is equal to a predetermined value of $\mu_{o}=0.10 \mathrm{~m}$

$$
H_{o}: \mu=\mu_{o}
$$

Interpretation of the predetermined value of $\mu_{o}=0.10 \mathrm{~m}$ has been presented in Krzyżek (2014). In each statistical analysis where the null hypothesis is defined, most frequently the main objective is to prove the alternative hypothesis. Therefore, for the null hypothesis, the alternative hypothesis $H_{1}$ has been defined, which is as follows: the mean value of $\mu$, for the differences in coordinates $d X, d Y$ and vector $d L$ in the combination of the methods - T-PPha, and for the tie distances $d R$ in the combinations of the methods $T-R, P P_{v a}-R, P P_{h a}-R-i$ is less than the predetermined value of $\mu_{0}$.

$$
H_{1}: \mu \leq \mu_{o}
$$


Having defined the two hypotheses, the mean value of $\mu$ was calculated (with respect to the parameters included in Tables 1-2, relative to any relationship in the individual methods).

An essential element used in subsequent calculations of statistical analysis was calculating the mean value of standard deviation $\delta$ from the formula

$$
\delta(\mu)=\frac{\hat{\delta}}{\sqrt{n}}
$$

where $\hat{\delta}$ - standard deviation for the differences in coordinates $\mathrm{dX}, \mathrm{dY}$ and vector $\mathrm{dL}$ in the combination of the methods $T-P P_{h a}$, and for tie distances $\mathrm{dR}$ in the combinations of the methods: $T-R, P P_{v a}-R, P P_{h a}-R$,

$\mathrm{n}$ - the number of differences in coordinates $\mathrm{dX}, \mathrm{dY}$ and vector $\mathrm{dL}$ in the combination of the methods $T$ - $P P_{h a}$, and for the distances $\mathrm{dR}$ in the combinations of the methods: $T-R, P P_{v a}-R, P P_{h a}-R$. 
g

\begin{tabular}{|c|c|c|c|c|c|c|c|c|c|c|}
\hline $9 \mathcal{E}$ & $0+0^{\circ} 0^{-}$ & $60 I^{\circ} 0$ & $\angle I^{\circ} 0$ & \multirow{9}{*}{\multicolumn{2}{|c|}{$\begin{array}{l}0 \\
0 \\
0 \\
0 \\
0\end{array}$}} & \multirow{9}{*}{$\mid \begin{array}{c}\tilde{b} \\
8 \\
0 \\
0\end{array}$} & \multirow{9}{*}{$\begin{array}{l}0 \\
0 \\
0 \\
0 \\
\dot{p} \\
0\end{array}$} & \multirow{28}{*}{$\tilde{m}$} & \multirow{28}{*}{ 菅 } & \multirow{9}{*}{ 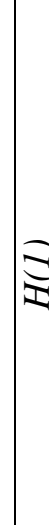 } \\
\hline$\subseteq \mathcal{E}$ & $\varsigma 00^{\circ} 0^{-}$ & $\angle \downarrow I^{\circ} 0$ & $\angle \nabla I^{\circ} 0$ & & & & & & & \\
\hline$\downarrow \mathcal{E}$ & $\angle I 0^{\circ} 0^{-}$ & $\varepsilon 00^{\circ} 0$ & $8 \mathrm{IO}^{\circ} 0$ & & & & & & & \\
\hline$\varepsilon \mathcal{E}$ & 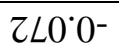 & $800^{\circ} 0$ & $\tau \angle 0^{\circ} 0$ & & & & & & & \\
\hline$\tau \varepsilon$ & $800^{\circ} 0^{-}$ & $\angle E 0^{\circ} 0$ & $8 \mathcal{E} 0^{\circ} 0$ & & & & & & & \\
\hline IE & $\mathrm{t} \mathrm{IO}^{\circ} 0^{-}$ & $\varsigma 00^{\circ} 0$ & SI0 0 & & & & & & & \\
\hline $0 \varepsilon$ & $\varepsilon 00^{\circ} 0^{-}$ & $820^{\circ} 0$ & $820^{\circ} 0$ & & & & & & & \\
\hline 62 & $920^{\circ} 0^{-}$ & $220^{\circ} 0$ & $\subseteq \mathcal{E} 0^{\circ} 0$ & & & & & & & \\
\hline 82 & $010^{\circ} 0$ & $010^{\circ} 0$ & $\nabla \mathrm{I} 0^{\circ} 0$ & & & & & & & \\
\hline$\angle Z$ & $910^{\circ} 0$ & $910^{\circ} 0$ & $\varepsilon z 0^{\circ} 0$ & $-\frac{\Xi}{z}$ & \multirow{10}{*}{\multicolumn{2}{|c|}{$\begin{array}{l}t \\
\stackrel{0}{0} \\
0 \\
0\end{array}$}} & \multirow{10}{*}{$\begin{array}{l}n \\
\\
\\
\\
1\end{array}$} & & & \\
\hline 92 & II $0^{\circ} 0$ & $\varepsilon 00^{\circ} 0^{-}$ & ZI0॰0 & \multirow{9}{*}{ 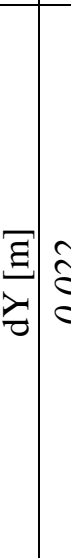 } & & & & & & \\
\hline$\varsigma Z$ & $9 \varepsilon 0^{\circ} 0$ & $\angle 00^{\circ} 0$ & $9 \varepsilon 0^{\circ} 0$ & & & & & & & \\
\hline$\nabla z$ & $\angle I 0^{\circ} 0^{-}$ & $\mathrm{IIO}^{\circ} 0^{-}$ & $0 Z 0^{\circ} 0$ & & & & & & & \\
\hline$\varepsilon z$ & $800^{\circ} 0$ & $800^{\circ} 0$ & IIO $0^{\circ} 0$ & & & & & & & $\approx$ \\
\hline$z z$ & $6 \mathrm{IO}^{\circ} 0^{-}$ & $9+0^{\circ} 0$ & $0 \varsigma 0^{\circ} 0$ & & & & & & & 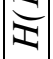 \\
\hline IZ & $900^{\circ} 0^{-}$ & $\varsigma \varepsilon 0^{\circ} 0$ & $\varsigma \varepsilon 0^{\circ} 0$ & & & & & & & \\
\hline $0 z$ & $\varsigma 00^{\circ} 0$ & $190^{\circ} 0$ & I90.0 & & & & & & & \\
\hline $6 \mathrm{I}$ & $\mathrm{ZI0^{ \circ } 0 ^ { - }}$ & $8 S^{\circ} 0$ & $090^{\circ} 0$ & & & & & & & \\
\hline $8 \mathrm{I}$ & $\mathrm{s}^{\circ} 0^{\circ} 0^{-}$ & $8 \angle 0^{\circ} 0$ & $060^{\circ} 0$ & & & & & & & \\
\hline$\angle I$ & $900^{\circ} 0$ & $010^{\circ} 0$ & ZI0०0 & \multirow{10}{*}{$\begin{array}{l}\underline{\Xi} \\
\bar{x} \\
z\end{array}$} & \multirow{9}{*}{$\begin{array}{l}\tilde{\delta} \\
\stackrel{0}{0}\end{array}$} & \multirow{9}{*}{\multicolumn{2}{|c|}{ 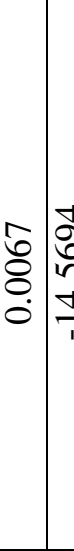 }} & & & \multirow{9}{*}{ 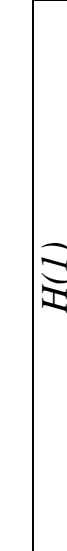 } \\
\hline 9I & $920^{\circ} 0^{-}$ & $\nabla \angle 0^{\circ} 0$ & $6 \angle 0^{\circ} 0$ & & & & & & & \\
\hline SI & $\angle S 0^{\circ} 0^{-}$ & $\varsigma 20^{\circ} 0$ & $290^{\circ} 0$ & & & & & & & \\
\hline$\nabla \mathrm{I}$ & $600^{\circ} 0$ & $8 \mathrm{IO}^{\circ} 0$ & $0 z 0^{\circ} 0$ & & & & & & & \\
\hline$\varepsilon \mathrm{I}$ & $920^{\circ} 0^{-}$ & $920^{\circ} 0$ & $\angle \varepsilon 0^{\circ} 0$ & & & & & & & \\
\hline ZI & $\varepsilon I 0^{\circ} 0^{-}$ & ZI0०0 & $8 \mathrm{IO}^{\circ} 0$ & & & & & & & \\
\hline II & $620^{\circ} 0^{-}$ & $\angle 90^{\circ} 0^{-}$ & $\varepsilon \angle 0^{\circ} 0$ & & & & & & & \\
\hline OI & $220^{\circ} 0$ & $\varsigma 20^{\circ} 0$ & $\varepsilon \varepsilon 0^{\circ} 0$ & & & & & & & \\
\hline 6 & $9 \varsigma^{\circ} 0$ & SI0*0- & $\angle S 0^{\circ} 0$ & & & & & & & \\
\hline 8 & $0 \mathcal{E}]^{\circ} 0$ & $9\left[0^{\circ} 0\right.$ & IE $I^{\circ} 0$ & \multirow{10}{*}{\multicolumn{2}{|c|}{ 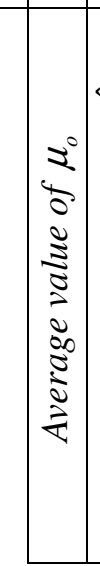 }} & \multirow{10}{*}{\multicolumn{2}{|c|}{ 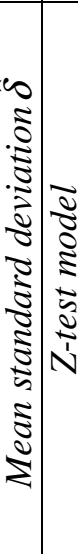 }} & & \multirow{10}{*}{ 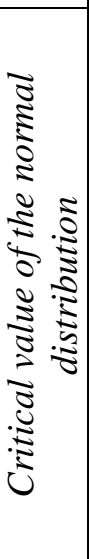 } & \\
\hline$L$ & $\angle Z I^{\circ} 0$ & $820^{\circ} 0^{-}$ & $0 \mathcal{E}^{\circ} 0$ & & & & & & & \multirow{9}{*}{ 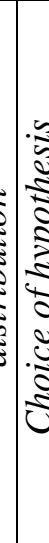 } \\
\hline 9 & IEO 0 & $800^{\circ} 0$ & $\tau \varepsilon 0^{\circ} 0$ & & & & & & & \\
\hline$\varsigma$ & $620^{\circ} 0$ & $100^{\circ} 0^{-}$ & $620^{\circ} 0$ & & & & & & & \\
\hline$t$ & $600^{\circ} 0$ & $\varsigma 20^{\circ} 0$ & $920^{\circ} 0$ & & & & & & & \\
\hline$\varepsilon$ & $0 \mathrm{IO}^{\circ} 0$ & $\nabla 20^{\circ} 0$ & $920^{\circ} 0$ & & & & & & & \\
\hline$\tau$ & $\varsigma 00^{\circ} 0^{-}$ & ऽI0 $0^{-}$ & $910^{\circ} 0$ & & & & & & & \\
\hline I & $200^{\circ} 0$ & $t 00^{\circ} 0^{-}$ & $700^{\circ} 0$ & & & & & & & \\
\hline 0 & {$[\mathrm{u}] \mathrm{Xp}$} & {$[\mathrm{w}] \mathrm{Xp}$} & [u]רp & & & & & & & \\
\hline Z & & ${ }^{p y} d d^{-}-L$ & & & & & & & & \\
\hline
\end{tabular}




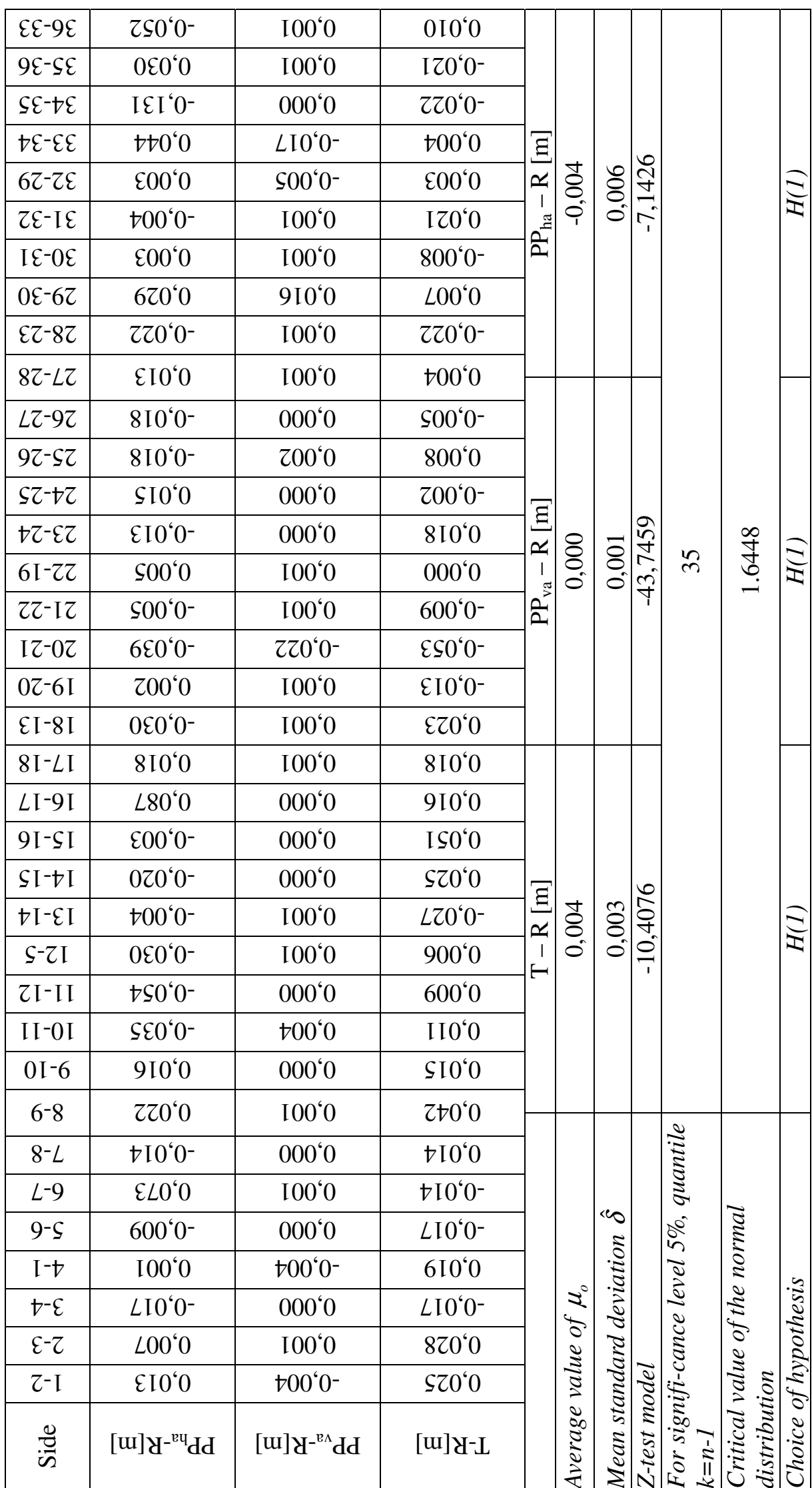


The last stage of the statistical analysis is to verify hypotheses made on the basis of the adopted model of the test $Z$ of a single mean value (formula 4), as well as the significance level $\alpha=5 \%$ and $k=n-1$ degrees of freedom together with the critical region constructed to the left, taking into account the quantile $z(\alpha)$.

$$
z=\frac{\mu-\mu_{o}}{\delta(\mu)}
$$

Analyzing the results contained in Table 1, the first important conclusion, but not the only one, is verification of the made hypotheses, which is unambiguous: the mean value of $\mu$, for the differences in coordinates $\mathrm{dX}, \mathrm{dY}$ and vector $\mathrm{dL}$ in combination of the methods $T$ - $P P_{h a}$, is statistically significant, resulting in the rejection of the hypothesis $\mathrm{H}_{0}$ in favor of the hypothesis $\mathrm{H}_{1}$. The values of the model of the test $Z$ of a single mean value are so high that the choice of the hypothesis is not random here, and even a change in the level of significance, e.g. to $\alpha=10 \%$ would have no effect on the final results. Another parameter affecting the assessment of effectiveness of the half-angle method is the mean value of coordinate differences, which for all values is even less than a half of the position error of the first-order accuracy detail: $\mathrm{dX}=0.002 \mathrm{~m}, \mathrm{dY}=0.022 \mathrm{~m}, \mathrm{dL}=$ $0.046 \mathrm{~m}$. An inherent attribute, which is also subject to the evaluation in the context of the obtained mean coordinate differences, is their formation with respect to all the corners of the buildings. When assessing the differences of coordinates $\mathrm{dX}, \mathrm{dY}$ and vector $\mathrm{dL}$, graphical presentation of the results contained in Table 1 and shown in Figure 3 can be used.

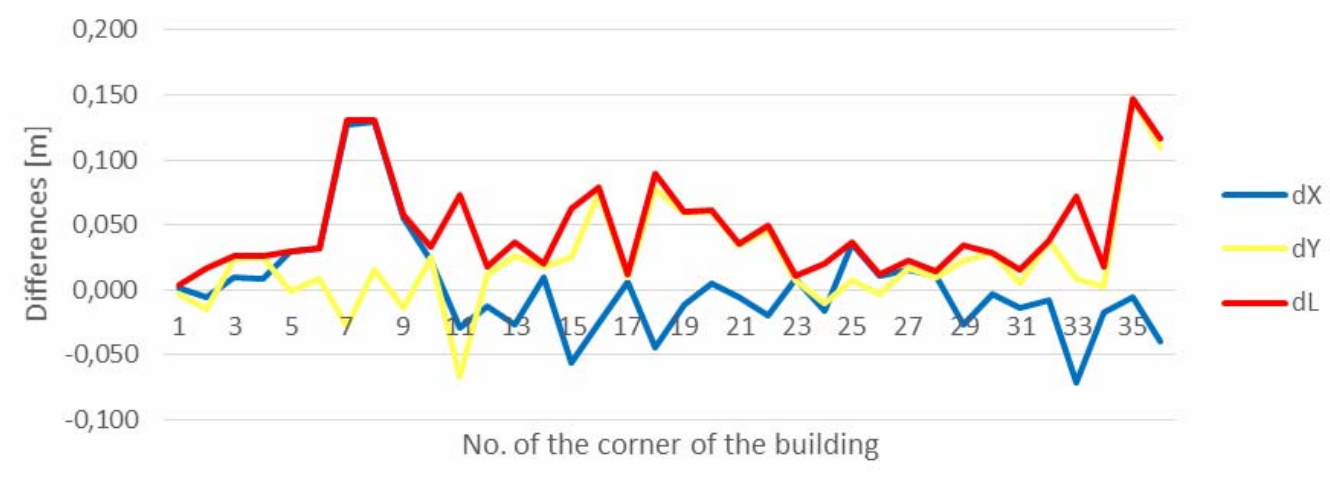

Fig. 3. Formation of differences in coordinates $d X, d Y$ and vector $d L$ in combination of the methods: tacheometric and line-line intersection modernized by the half-angle method.

If we analyze the values of coordinate differences $\mathrm{dX}$ and $\mathrm{dY}$, we see that for a definitely greater number of points (building corners), they fall within the range of $\pm 0.05 \mathrm{~m}$. Only three points for the parameters $\mathrm{dX}(7,8,33)$, six points for the $\mathrm{dY}$ values $(11,16,18,20,35,36)$, and eleven points for dL $(7,8,11,15,16,18,19,20,33,35,36)$ exceeded this small value of $\pm 0.05 \mathrm{~m}$. The interval with the scale of $\pm 0.05 \mathrm{~m}$ is frequent for the occurrence of coordinate differences in total station measurements of the same objects (details of the first-order accuracy), measured by different surveyors. The reasons for it can be sought at various levels, for example nonhomogeneity of the control network, accuracy of measuring instruments, and others (Kowalczyk, 2011). Therefore, when we compare two very different measurement techniques (RTNGNSS and tacheometry), differences in the coordinates of up to $\pm 0.05 \mathrm{~m}$ do not seem very important. However, when we consider the boundary value of the accuracy of location of the first-order accuracy details $( \pm 0.10 \mathrm{~m})$ in the formation of coordinate differences, then the analyzed parameters $(\mathrm{dX}, \mathrm{dY}, \mathrm{dL})$ differ significantly from it. For the values of $\mathrm{dX}$ and $\mathrm{dY}$ just two points $(7,8$, and 35,36 , respectively) exceed the predetermined threshold $( \pm 0.10 \mathrm{~m})$, which automatically translates into exceeding $\pm 0.10 \mathrm{~m}$ of the above-mentioned four points for the parameter $\mathrm{dL}$. Although the values of several 
centimeters are already significant in the formation and analyzing individual attributes of the coordinates, exceeding the maximum position error of details of the first-order accuracy is not that big and it does not exceed $\pm 0.13 \mathrm{~m}$. Additionally, we should take into account that in the case of these four points there were difficult field conditions for RTN GNSS technology (horizon obscured by buildings and trees). In the final stage of assessing the suitability of the half-angle method in line-line intersection in the context of the obtained coordinates, the incidence of coordinate differences in individual intervals and their percentage contribution to these extremes should be considered. For this purpose, three histograms were created (Fig. 4-6) for the coordinate differences $\mathrm{dX}, \mathrm{dY}$ and vector differences $\mathrm{dL}$, establishing intervals at $\pm 0.02 \mathrm{~m}$. For all the three analyzed attributes, the greatest number of the occurring coordinate differences falls within the intervals of small values. For example, for the interval $\pm 0.04 \mathrm{~m}$, the incidence of $\mathrm{dX}$ coordinate differences is $81 \%$, of $\mathrm{dY} 78 \%$ and $64 \%$ for the vector $\mathrm{dL}$. When we increase the interval to $\pm 0.10 \mathrm{~m}$, then the percentage of individual parameters increases significantly, adopting the following values: $97 \%$ for $\mathrm{dX}, 91 \%$ for $\mathrm{dY}, 88 \%$ for $\mathrm{dL}$. A thorough analysis of the coordinate differences allows to evaluate the method of line-line intersection modernized by the half-angle method as significantly increasing the reliability of determining the location of the corners of buildings. Still, some doubts remain as to the occurrence, although to a small extent, of the values exceeding $\pm 0.10 \mathrm{~m}$, which motivate the author to carry out further research aimed at reducing the existing discrepancies.

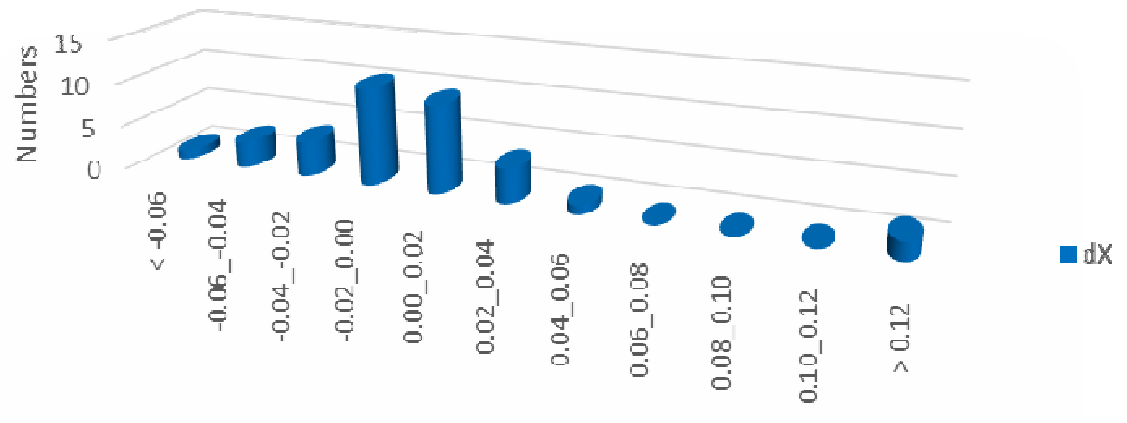

Intervals

Fig. 4. Histogram of the measured frequency of the coordinate differences $\mathrm{dX}$ at the corners of the building in the combination of the methods: tacheometric and line-line intersection modernized by the half-angle method.

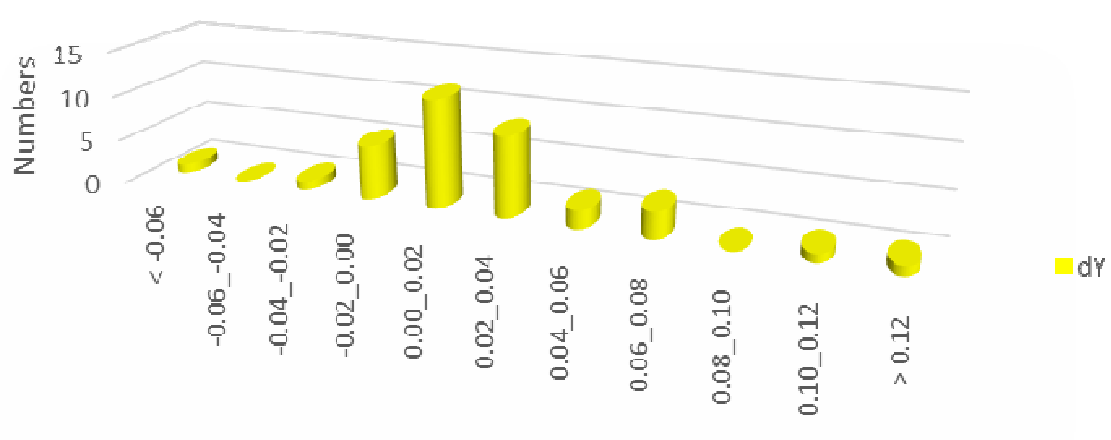

Intervals

Fig. 5. Histogram of the measured frequency of the coordinate differences $d Y$ at the corners of the building in the combination of the methods: tacheometric and line-line intersection modernized by the half-angle method. 


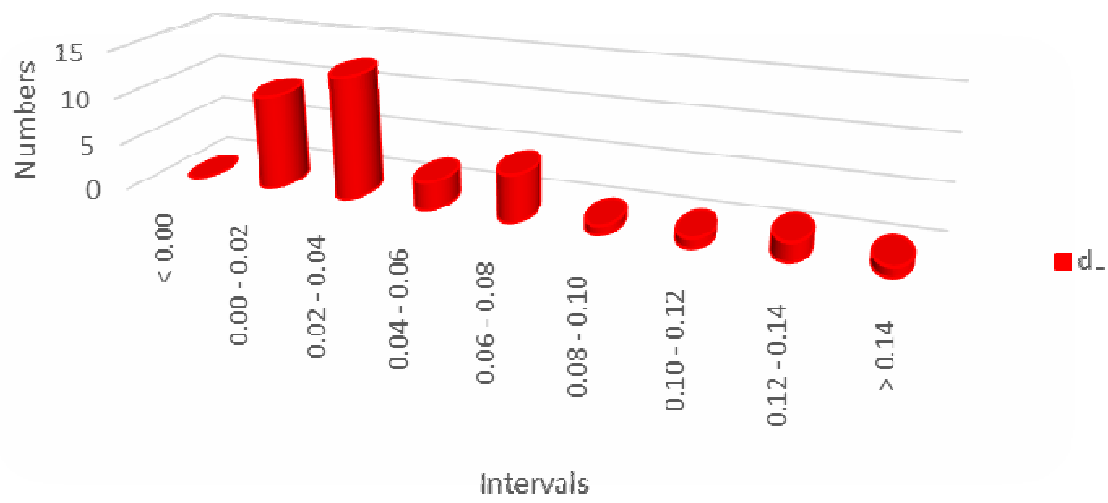

Fig. 6. Histogram of the measured frequency of the vector dL differences at the corners of the building in the combination of the methods: tacheometric and line-line intersection modernized by the half-angle method.

In order to illustrate even better the effect of the half-angle method on the final results of determining the corners of the building, a comparison was made of the results of using the classical method of line-line intersection and the line-line intersection modernized by the half-angle method employing RTN GNSS technology. Between the two methods, the mean values of coordinate differences $d X, d Y, d L$ were compared (Fig. 7), and the intervals regarding the values of minimum coordinate differences $\mathrm{dX}, \mathrm{dY}, \mathrm{dL}$ (Fig. 8) as well as the maximum values of coordinate differences dX, dY, dL (Fig. 9). The terms before and after in Figures 7-9 respectively refer to the use of either the classical method of line-line intersection (before) or the line-line intersection modernized by the half-angle method (after).

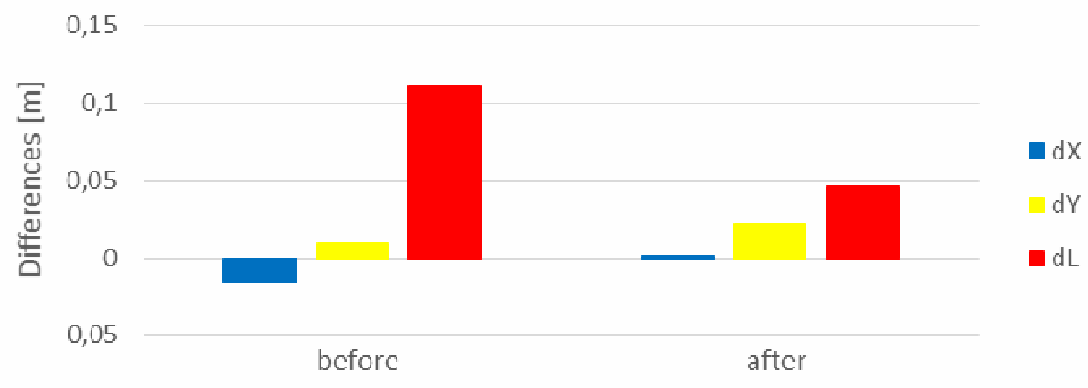

Fig. 7. Mean values of coordinate differences $d X, d Y, d L$ before and after the use of the line-line intersection method modernized by the half-angle method.

Before using the method of half-angle, the mean coordinate differences were at the level of $\mathrm{dX}$ : $-0.015 \mathrm{~m}$, dY: $0.009 \mathrm{~m}$, and dL: $0.111 \mathrm{~m}$. As it can be seen in Fig. 7 , the values of $\mathrm{dX}$ and $\mathrm{dL}$ have decreased to $0.002 \mathrm{~m}$ and $0.046 \mathrm{~m}$, respectively, which represents a decrease of $87 \%$ and $59 \%$. Only the values of $\mathrm{dY}$ have increased to the level of $0.022 \mathrm{~m}$, which, however, is a small, almost negligible increment taking into account other accuracy aspects, e.g. the accuracy of determining the coordinates X, Y using RTN GNSS surveying technology, that is $\pm 0.03 \mathrm{~m}$. 


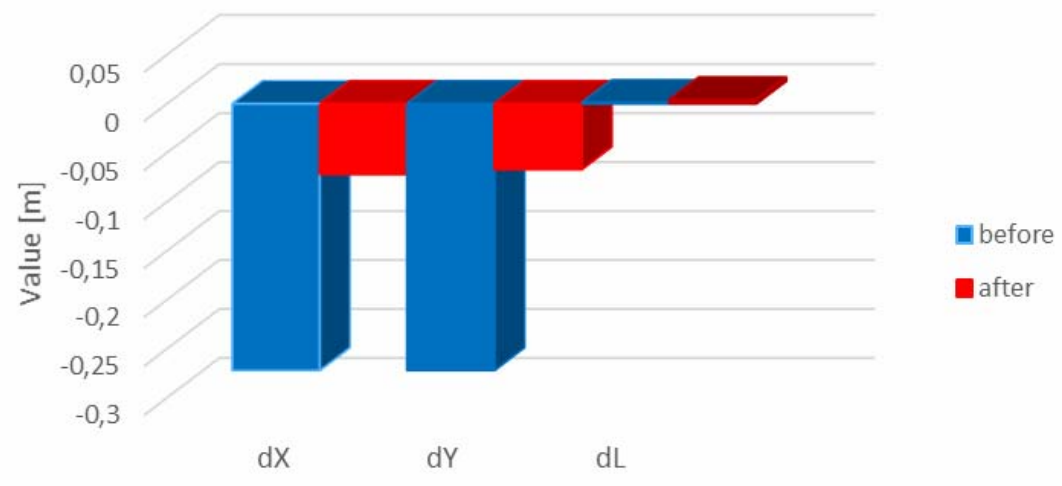

Fig. 8. The minimum values of coordinate differences $d X, d Y, d L$ before and after the use of the line-line intersection method modernized by the half-angle method.

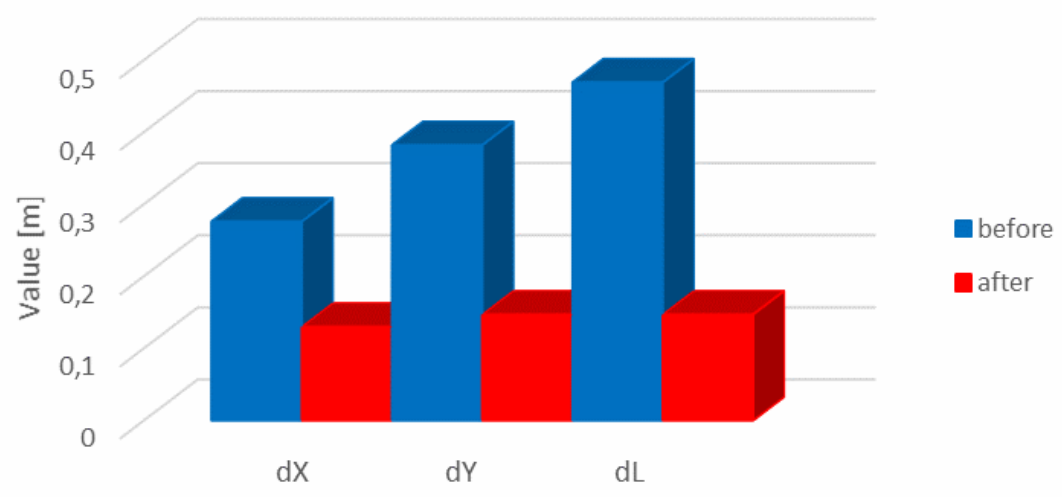

Fig. 9. The maximum values of coordinate differences $d X, d Y, d L$ before and after the use of the line-line intersection method modernized by the half-angle method.

A similar situation has been presented in the comparison of the results (Fig. 8-9) regarding the extreme values of coordinate differences. For the minimum values (Fig. 8), the coordinate differences $\mathrm{dX}, \mathrm{dY}$ and $\mathrm{dL}$ have changed, respectively, from $-0.272 \mathrm{~m},-0.272 \mathrm{~m}$ and $0.001 \mathrm{~m}$ to $0.072 \mathrm{~m},-0.067 \mathrm{~m}$ and $0.004 \mathrm{~m}$. For the parameters $\mathrm{dX}$ and $\mathrm{dY}$ it is a decrease of $74 \%(\mathrm{dX})$ and $75 \%$ (dY). The minimum value of the vector $\mathrm{dL}$ has increased slightly, only by about $0.003 \mathrm{~m}$. However, in the case of the maximum values (Fig. 9), all the three parameters have been reduced. The maximum differences of $\mathrm{dX}$ coordinates have decreased from $0.276 \mathrm{~m}$ to $0.130 \mathrm{~m}$ (a decrease of $53 \%$ ), dY parameter has changed from $0.382 \mathrm{~m}$ to $0.147 \mathrm{~m}$ (a decrease of $62 \%$ ) and the vector $\mathrm{dL}$ has reduced its values from $0.469 \mathrm{~m}$ to $0.147 \mathrm{~m}$ level (a decrease of $69 \%$ ).

All of the results presented in Table 1, as well as their graphical representation in Fig. 3-9, backed by a thorough analysis, strongly support the use of the method of half-angle in intersection of straight lines for determining the corners of buildings. However, in order to have a complete picture of the formation of all possible parameters which have a direct influence on the quality of this novel method, the mutual relationships in the check measurements of the building corners, or the tie distances, remained to be analyzed. Their exact presentation has been contained in Table 2 . Below, to visualize the results illustrated in Table 2, the formation of the tie distances between the individual corners of the buildings has been shown in a graphical form (Fig. 10). 


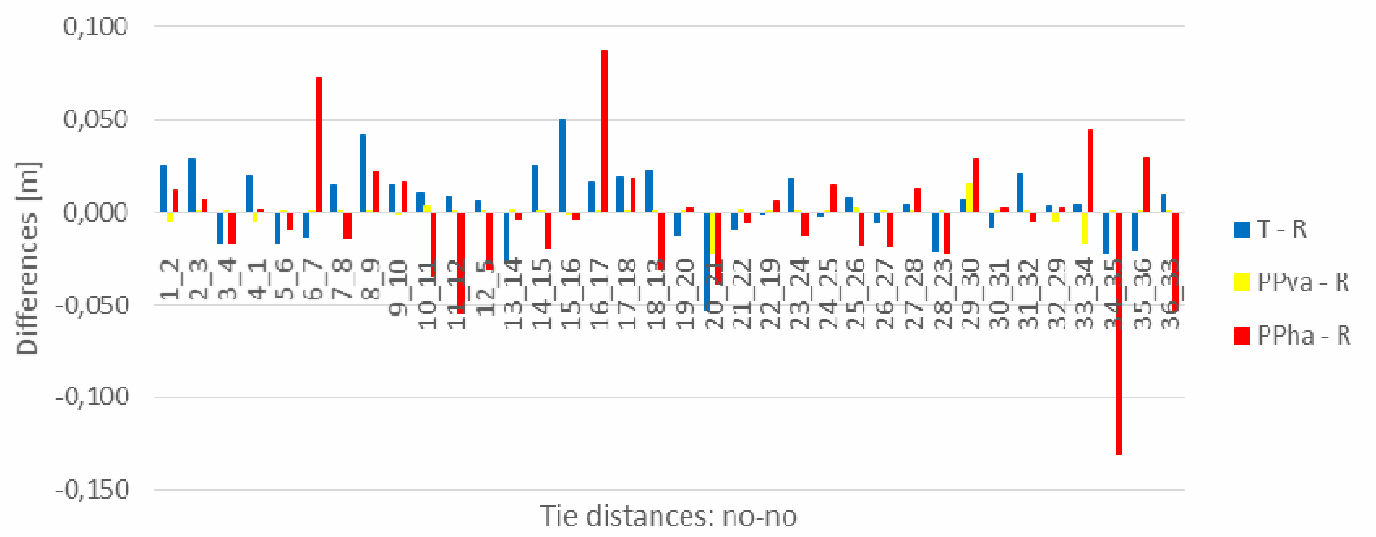

Fig. 10. Differences in tie distances $d R$ in combination of the methods: tacheometric, line-line intersection method taking into account the method of vector addition and line-line intersection modernized by the half-angle method.

The mean value of the differences in tie distances $d R$ (Tab. 2) in the combinations of methods: $T-R, P p_{v a}-R, P p_{h a}-R$, which is at the level of single millimeters $( \pm 0.004 \mathrm{~m})$, and the rejection of the null hypothesis in favor of the alternative hypothesis, confirms the assumption of the high efficiency of the half-angle method applied to modernize the line-line intersection method. However, as it was in the case of coordinate differences, also in analyzing the differences in tie distances $d R$, their formation should be verified for all the building walls. Figure 10 shows that the vast majority of the differences in tie distances for all three summarized methods falls within $\pm 0.05 \mathrm{~m}$, which is a very good result. But when we look more closely at individual values (Tab. 2 and Fig. 10), a definite advantage of the $P P_{v a}$. method can be seen. In this method, the differences in the tie distances $d R$ are at the level of single millimeters (only two sides exhibit differences at the level of $\pm 0.02 \mathrm{~m}$ ), which perfectly reflects the geometric structure of the building, but leaves some doubt as to the reliability of the coordinates. Also, a classical measurement method, that is tacheometry, yields good results, in which the differences in tie distances, although generally larger than the $P P_{v a}$ method, are still at a low level: for 10 points $d R<0.01 \mathrm{~m}$, and for the remaining ones $\pm 0.05 \mathrm{~m}$. Unfortunately, when compared with the methods of $T$ and $P P_{v a}$, the method of $P P_{h a}$ is classified in the last position, but that does not rule out its usefulness. For the three walls of the buildings, the values of $\pm 0.05 \mathrm{~m}$ of the differences in tie distances are exceeded, and for one they are even $\pm 0.10 \mathrm{~m}$. For the sides 6-7 and 34-35 (building corners), large values of differences in tie distances can partially be explained by significant (exceeding $\pm 0.10 \mathrm{~m}$ ) values of coordinate differences $\mathrm{dX}$ (point 7), $\mathrm{dY}$ (point 35) and vector $\mathrm{dL}$ (points 7 and 35). In turn, for the side 16-17 $(\mathrm{dR}=0.087 \mathrm{~m})$ there were difficult conditions for the linear measurement (with an open-frame tape measure), as well as for the RTN GNSS surveys. Also, coordinate differences for point 16, which were for $\mathrm{dY}=0.074 \mathrm{~m}$ and for $\mathrm{dL}=0.079 \mathrm{~m}$, could have had a direct impact on the differences in tie distances $\mathrm{dR}$ which occurred for the side 16-17. However, regardless of the occurrence of significant differences in tie distances for the three walls of the buildings, it should be emphasized that, for the other $92 \%$ of the check measurements, the differences in results were at the level of $\pm 0.05 \mathrm{~m}$. Taking into account some imperfections of the half-angle method used to modernize the method of line-line intersection, it should be objectively stated, as it is evident from the study, that the use of this innovative solution in RTN GNSS measurements to determine the corners of buildings significantly increases the reliability of determining the coordinates of the sought points.

\section{SUMMARY AND CONCLUSIONS}

In the presented research experiment, the main objective was to identify new technical and algorithmic possibilities, which would significantly contribute to increasing the reliability of 
determining Cartesian coordinates X, Y, of corners of buildings with the use of RTN GNSS technology. For natural reasons (the obscured horizon), it is very difficult, sometimes even impossible, to locate the GNSS receiver directly at the corner of a building. Therefore, real-time measurements are supported by indirect methods of measurement, for example distance-distance intersection, a point on a straight line, or line-line intersection (Krzyżek, 2014). In the case of an indirect method of line-line intersection, a major problem is setting out precisely base points to the appropriate reference line, relative to the corner of a building. A building determined in this way is often geometrically deformed. The use of the method of vector addition is an alternative at this point (the results of research experiments on this method have been examined in detail by the author). Unfortunately, there are still doubts as to the reliability of the modified coordinates of the building corners after the verification by the method of vector addition. Therefore, it seems that yet another author's proposal modernizing the method of line-line intersection, called the half-angle method, substantially modifies the measurement results, giving them greater reliability. It obviously is not a perfect method, and has its advantages and disadvantages, as every other method does. An undeniable advantage is not only the ease and short time of measurement of a building, but also, and perhaps above all, a relatively high accuracy of determining the location of points. Making a positive assessment of the results modified by the method of half-angle, it should be borne in mind that it is only a component of the entire technology applied, i.e. RTN GNSS measurements and indirect method of line-line intersection. Although each assessment is somehow subjective, it can be objectively concluded that this innovative proposal certainly improves the performance results ( $\mathrm{X}$ and $\mathrm{Y}$ coordinates), giving them values which are convergent to the most probable ones to a greater degree than the classical method of line-line intersection. Unfortunately, a significant disadvantage is the limitation of its application. As it was already mentioned, it is used to verify squareness of the walls (construction project requirements). Thus, any deviations from this standard eliminate or restrict the full use of the new solution. In such situations, integrated RTN GNSS surveys and tacheometry can be an alternative. The research experiment also identified, for a small number of points being determined, differences in coordinates ( 4 points) and tie distances ( 1 point) relative to the reference parameters, exceeding the permissible error of a detail of the first-order accuracy, that is $\pm 0.10 \mathrm{~m}$. This is an argument that still motivates the author to continue his search for even better solutions, which would allow to fully use the modernized method of line-line intersection during RTN GNSS measurements aimed at determining the position of the corners of buildings.

To sum up, it can definitely be concluded that the optimization of the method of line-line intersection, used in real-time measurements by employing the method of half-angle, will contribute to a greater accuracy of determining corners of buildings and will provide a more precise reflection of the geometric shape of a structure.

Acknowledgments. This work was carried out within the statutory studies of the AGH University of Science and Technology, Faculty of Mining Surveying and Environmental Engineering No. 11.11.150.006.

\section{REFERENCES:}

Cai Ch., Gao Y. (2013). Modeling and assessment of combined GPS/GLONASS precise point positioning. GPS Solutions, 17, Issue 2, 223-236.

Ge L., Lee I. (2006). The performance of RTK-GPS for surveying under challenging environmental conditions. Earth, Planets and Space, 58, Issue 5, 515-522.

Kowalczyk K. (2011). Analysis of the errors generated during the measurement of situational details RTK GPS method. Acta Scientiarum Polonorum Geodesia et Descriptio Terrarum, 10(1), 5-22. 
Krzyżek R. (2014). Reliability analysis of the results of RTN GNSS surveys of building structures using indirect methods of measurement. Geodesy and Cartography, 63, no. 2, 161-181.

Krzyżek R. (2013). Verification of applicability of the Trimble RTX satellite technology with xFill function in establishing surveying control networks. Geodesy and Cartography, 62, no. 2, 217233.

Krzyżek R. (2014). Precision analysis of Trimble RTX surveying technology with xFill function in the context of obtained conversion observations. Reports on Geodesy and Geoinformatics, Vol. 97, 47-70.

Pirti A., Yucel M., Gumus K. (2013). Testing Real Time Kinematis GNSS (GPS and GPS/GLONASS) methods in obstructed and unobstructed sites. Geodetski Vestnik, 57, no. 3, 498-512.

Zhang X. \& Li P. (2014). Integrating GPS and GLONASS to accelerate convergence and initialization times of precise point positioning. GPS Solution, 18, Issue 3, 461-471.

www.mapy.geoportal.gov.pl/imap. (2014). - the state of the 13.11.2014.

Received: 2014-12-16,

Reviewed: 2015-01-20, by Z. Siejka,

Accepted: 2015-03-02. 